\begin{tabular}{l|l}
\hline IISTEMA \\
DEETONICO REVISTAS \\
SER I UFPR
\end{tabular}

\title{
Metodologia do diagnóstico interdisciplinar: a construção de um quadro de trabalho comum
}

\author{
Claude RAYNAUT ${ }^{1}$, Angela Duarte Damasceno FERREIRA ${ }^{2}$ \\ ${ }^{1}$ Antropólogo, Doutor em Antropologia, directeur de recherche au Centre National de la Recherche Scientifique, Universidade de Bordeaux 2 \\ Victor Segalen, França \\ ${ }^{2}$ Socióloga, Doutora em Sociologia, professora do Departamento de Ciências Sociais da UFPR
}

Conforme a metodologia geral adotada na orientação do trabalho da primeira turma do Doutorado (cf. Introdução), a elaboração do programa de pesquisa a ser desenvolvido no meio urbano do litoral passou por uma série de etapas, que permitiram a construção progressiva dos temas de investigação, dos assuntos de tese e a elaboração de instrumentos de trabalho coletivo, oferecendo um quadro referencial comum para os trabalhos individuais. É esta progressão que nós vamos apresentar, nas suas grandes linhas, neste capítulo.

\section{Do diagnóstico geral à identificação de um objeto e de uma problemática de pesquisa}

A primeira etapa da realização do diagnóstico dos problemas que se colocam nas aglomerações urbanas do litoral paranaense consistiu em reunir informações e dados sobre vários domínios de observação, que correspondiam às grandes lógicas em função das quais se estruturava, conforme o enfoque geral do Doutorado, a análise das relações entre sociedades e natureza (cf. Introdução):

- Demografia e saúde;

- Dimensões materiais e técnicas do fenômeno de urbanização (infraestrutura, equipamentos coletivos etc.);

- Dimensões sociais da dinâmica da sociedade urbana (diferenciação socioeconômica, pobreza, associativismo e movimentos sociais, relações de poder e instituições públicas);

- Dinâmicas econômicas (atividades industriais, comerciais e de serviços, mercado de trabalho, efeito de fatores exteriores sobre a economia local).

Para cada um destes grandes domínios de observação, procurou-se identificar as consequências observadas no domínio do meio ambiente.

\footnotetext{
* Publicado originalmente em: Raynaut, C. et al. (Eds.). Desenvolvimento e meio ambiente: em busca da interdisciplinaridade: pesquisas urbanas e rurais. Parte I, Capítulo 1. Curitiba: Ed. da UFPR, 2002. p. 29-41.
} 
Os alunos compartilharam as tarefas de coleta de dados secundários e de entrevistas com informantes-chave. Encontros informais e oficinas de pesquisa organizadas pelo corpo docente do Doutorado lhes permitiram trocar informações reunidas e desenvolver um esforço de reflexão sintética sobre elas. Dentro do conjunto complexo e diversificado dos dados levantados no decorrer do diagnóstico, destacou-se progressivamente um problema central ao qual, de um modo ou de outro, se remetia a maioria dos problemas urbanos do litoral: a polaridade da cidade de Paranaguá na região. Maior saída para o escoamento da produção agrícola do interior do Paraná, bem como do Paraguai, o porto conhecera um desenvolvimento muito rápido a partir dos anos 60. Essa intensificação das atividades portuárias se acompanhou de grandes mudanças, tanto da organização espacial da cidade (deslocamento do porto, extensão rápida da aglomeração nas cercanias de sua nova localização) como do tamanho, da composição, da estruturação social e política de sua população (crescimento acelerado, chegada de migrantes, surgimento de novos embates políticos e conflitos sociais). Mais recentemente, o porto e a cidade passaram por transformações radicais (a modernização do porto e o deslocamento de algumas atividades portuárias para o interior do Estado), que foram o reflexo das grandes transformações da economia do Paraná e brasileira, assim como da economia mundial. Hoje, se colocam em Paranaguá problemas de desenvolvimento e problemas ambientais que são os desdobramentos desta evolução histórica e das mudanças atualmente em curso.

Sem dúvida, problemas importantes encontram-se também em outras cidades e aglomerações urbanas do litoral. Em particular, é o caso do conjunto de balneários que se avultam à beira do curto trecho da orla marítima paranaense. Lá, grandes problemas urbanísticos e ambientais surgem co- mo resultado da alta concentração da população veranista durante a temporada e das construções desordenadas que marcaram sua ocupação. Contudo, foi decidido concentrar o esforço de pesquisa do grupo sobre o caso de Paranaguá. Vários motivos justificaram essa escolha:

- além da centralidade da posição da cidade em relação às dinâmicas que percorrem a economia e a sociedade do litoral, seu tamanho, em termos demográficos (95.782 habitantes em 1991, segundo o Censo Demográfico do IBGE-1991), é mais expressivo que o das demais aglomerações da região e a força das evoluções econômicas e urbanísticas às quais esteve submetida na sua história recente, permite considerá-la como um caso pertinente para conduzir reflexões de caráter mais geral sobre as relações sociedade e quadro de vida, num ambiente urbano;

- por outro lado, o fato de ela ser uma cidade média facilita uma abordagem global do espaço urbano e de seus habitantes e viabiliza a análise das heterogeneidades locais, nas suas diversas formas de expressão (tanto espacial como socioeconômica).

Feita esta escolha, iniciou-se o trabalho de construção da problemática comum que ia articular as pesquisas particulares dos diversos pesquisadores. Elaborou-se, então, um modelo que resumia, de um modo esquemático e sintético, os diferentes fatores e as diversas · interações presentes nas dinâmicas das relações entre a sociedade urbana e seu meio ambiente. A Figura 1 propõe uma representação gráfica deste modelo.

Esta figura organiza-se em torno de um núcleo central que corresponde à interseção de dois sistemas: a sociedade urbana de um lado, a cidade como espaço físico-natural, de outro. Em cada um figuram as variáveis dos sistemas sobre os quais dispunham-se de dados fornecidos pelo diagnóstico. $\mathrm{Na}$ interface entre os dois sistemas estão listadas 


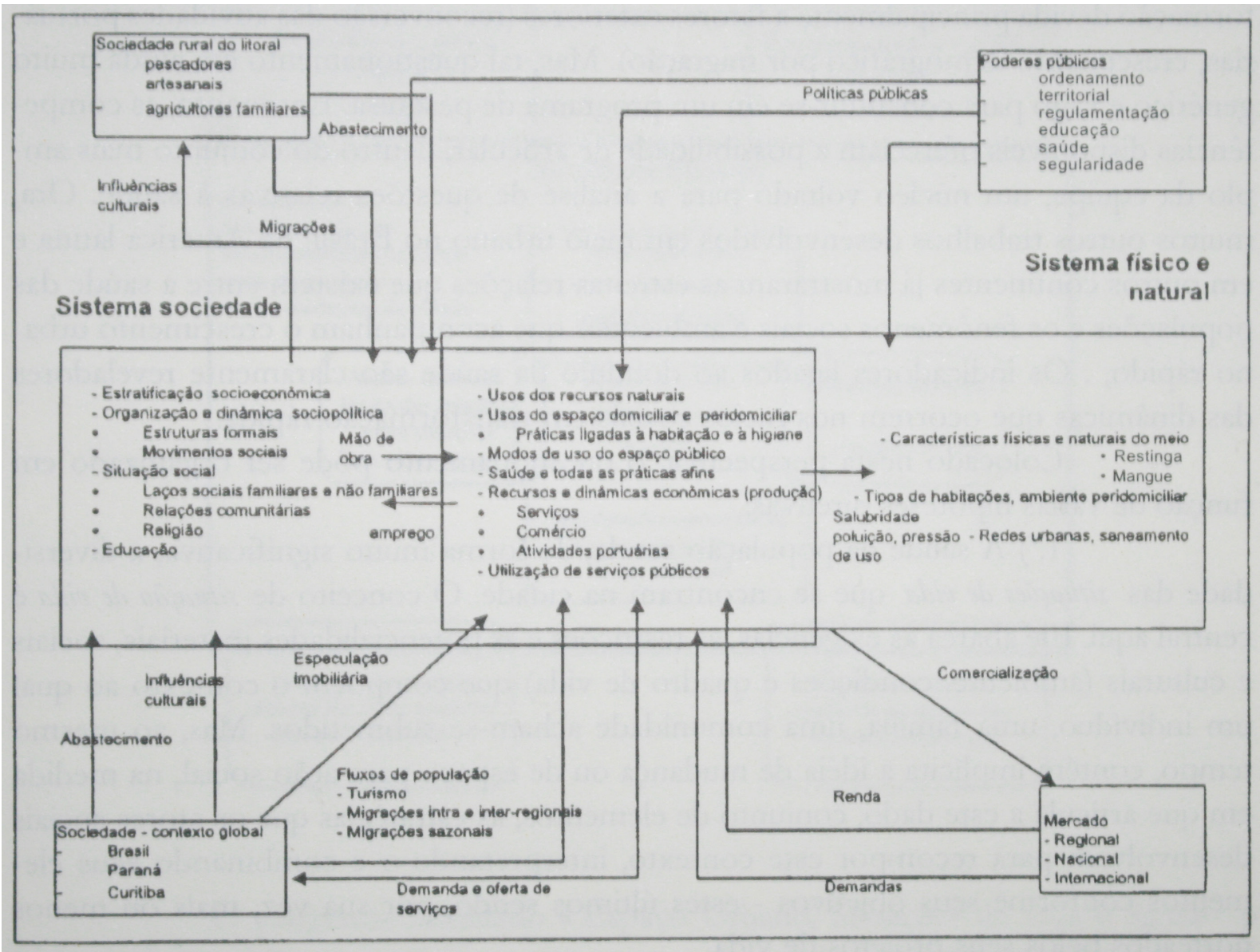

FIGURA 1 - Modelo das dinâmicas das relações entre sociedade e meio natural na área urbana de Paranaguá.

algumas questões críticas referentes às relações população/meio ambiente, que foram identificadas durante essa etapa do trabalho. Na periferia deste núcleo central estão indicados vários "sistemas externos" cuja influência, tanto sobre a sociedade urbana quanto sobre a cidade como espaço físico, pôde igualmente ser documentada no diagnóstico.

Este modelo dá uma representação muito simplificada dos dados coletados, mas ele constitui um instrumento prático para hierarquizar e situar os fatos dentro de uma perspectiva global e dinâmica.
Por isso, ele serviu de base de discussão para efetuar as escolhas e estabelecer as prioridades com vistas à elaboração do programa de pesquisa comum.

Uma das principais conclusões dessa fase foi de que a cidade de Paranaguá atravessara, no curso do último meio século, um período de transformações profundas e que, atualmente, entrava em um novo ciclo de transição. A chave desta evolução reside nas relações complexas que a cidade mantém com seu porto e no crescimento demográfico e espacial que ali se verificou. Partindo 
destas verificações, identificou-se um conjunto de questões ligadas umas às outras e susceptíveis de reunir as competências e os interesses dos diversos alunos engajados no programa:

- Qual é o impacto atual dessas dinâmicas globais sobre o espaço urbano, considerado aqui como quadro de vida?

- Como a população urbana se distribui de forma diferenciada nesse espaço?

- Quais são as formas de diferenciação social que vêm operando nesse contexto?

- Como os diferentes atores sociais (formais e informais, organizados ou obedecendo a estratégias individuais) atuam na gestão do espaço urbano?

Tratava-se, no final das contas, de questionar a dinâmica das relações população/meio ambiente dentro de um espaço urbano submetido a uma rápida transformação devida principalmente a fatores exteriores (reconversão das atividades portuárias, crescimento demográfico por migração). Mas, tal questionamento era ainda muito genérico e vago para constituir-se em um programa de pesquisa. Entretanto, as competências disponíveis ofereciam a possibilidade de articular, dentro do conjunto mais amplo da equipe, um núcleo voltado para a análise de questões relativas à saúde. Ora, muitos outros trabalhos desenvolvidos em meio urbano no Brasil, na América Latina e em outros continentes já mostraram as estreitas relações que existem entre a saúde das populações e os fenômenos sociais e ambientais que acompanham o crescimento urbano rápido. Os indicadores ligados ao domínio da saúde são claramente reveladores das dinâmicas que ocorrem nos meios sociais em transformação rápida.

Colocado nesta perspectiva, o questionamento pôde ser organizado em função de várias hipóteses diretivas:

1. $\left.{ }^{a}\right)$ A saúde da população revela, de forma muito significativa, a diversidade das situações de vida que se encontram na cidade. O conceito de situação de vida é central aqui. Ele abarca as exigências, as restrições e as potencialidades materiais, sociais e culturais (ambiente, condições e quadro de vida) que compõem o contexto ao qual um indivíduo, uma família, uma comunidade acham-se submetidos. Mas, ao mesmo tempo, contém implícita a ideia de mudança ou de espaço para ação social, na medida em que articula a este dado conjunto de elementos as estratégias que os atores sociais desenvolvem para recompor este contexto, interpretando-o e combinando seus elementos conforme seus objetivos - estes últimos sendo, por sua vez, mais ou menos norteados pelos seus projetos de vida.

2. ${ }^{\text {a) }}$ A diversidade de situações de vida e de níveis de vulnerabilidade à doença, encontrados numa cidade, são a expressão das dinâmicas que movimentam a sociedade urbana no seu conjunto, principalmente no que diz respeito aos processos de diferenciação econômica, social e cultural.

3. ${ }^{\text {a) }}$ Esta diferenciação manifesta-se, de forma parcial, porém, legível, nas heterogeneidades do espaço urbano (estrutura, funções, equipamentos, redes) e nas diferenciações socioeconômicas: ambos sendo o produto de fatores histórico-sociais, demográficos, econômicos, materiais, articulados de forma mais ou menos voluntária pela política urbana.

Mas, para entender as dinâmicas de diferenciação social e espacial existentes na cidade, bem como suas consequências sobre as relações populações/ meio ambiente, é preciso também poder analisar o contexto de determinação mais amplo dentro do qual essas relações inscrevem-se. A este respeito, as competências disponíveis na equipe tornaram possível o estudo de um certo número de temas importantes ligados ora à sociedade urbana e sua economia, ora à cidade como espaço físico-natural. Puderam assim ser identificados vários assuntos de 
tese susceptíveis de contribuir à exploração do contexto dentro do qual as questões mais diretamente voltadas para a análise das situações de vida e para o estudo de suas consequências sanitárias eram colocadas.

A Figura 2 resume, sob uma forma gráfica, a proposta de articulação entre as diversas pesquisas de tese individuais, que foi elaborada ao cabo de um longo processo de amadurecimento que se operou durante a fase de diagnóstico. A posição central do tema da saúde não significava que todos deveriam trabalhar sobre questões referentes a este campo. Esperava-se, sim, que cada um contribuísse, de perto ou de longe, à análise de um aspecto do funcionamento da sociedade urbana e da cidade para alimentar a compreensão das relações populações/ meio ambiente, no âmbito das quais a saúde constituía um revelador significativo.

O programa intitulado "Espaço Urbano, Situações de Vida e Saúde: o caso de Paranaguá", constituiu-se assim numa síntese dos questionamentos comuns e interfaces entre os alunos e serviu como orientação para o detalhamento dos projetos individuais de pesquisa apresentados e qualificados no final do mesmo ano.

É claro que este programa está longe de cobrir todas questões levantadas pela problemática das relações sociedade/meio ambiente no quadro urbano. Ele apenas representa um esforço de leitura coerente e articulada de algumas facetas desta realidade. Apesar disto, sua pretensão talvez tenha sido muito grande, em função do fato de que exigia

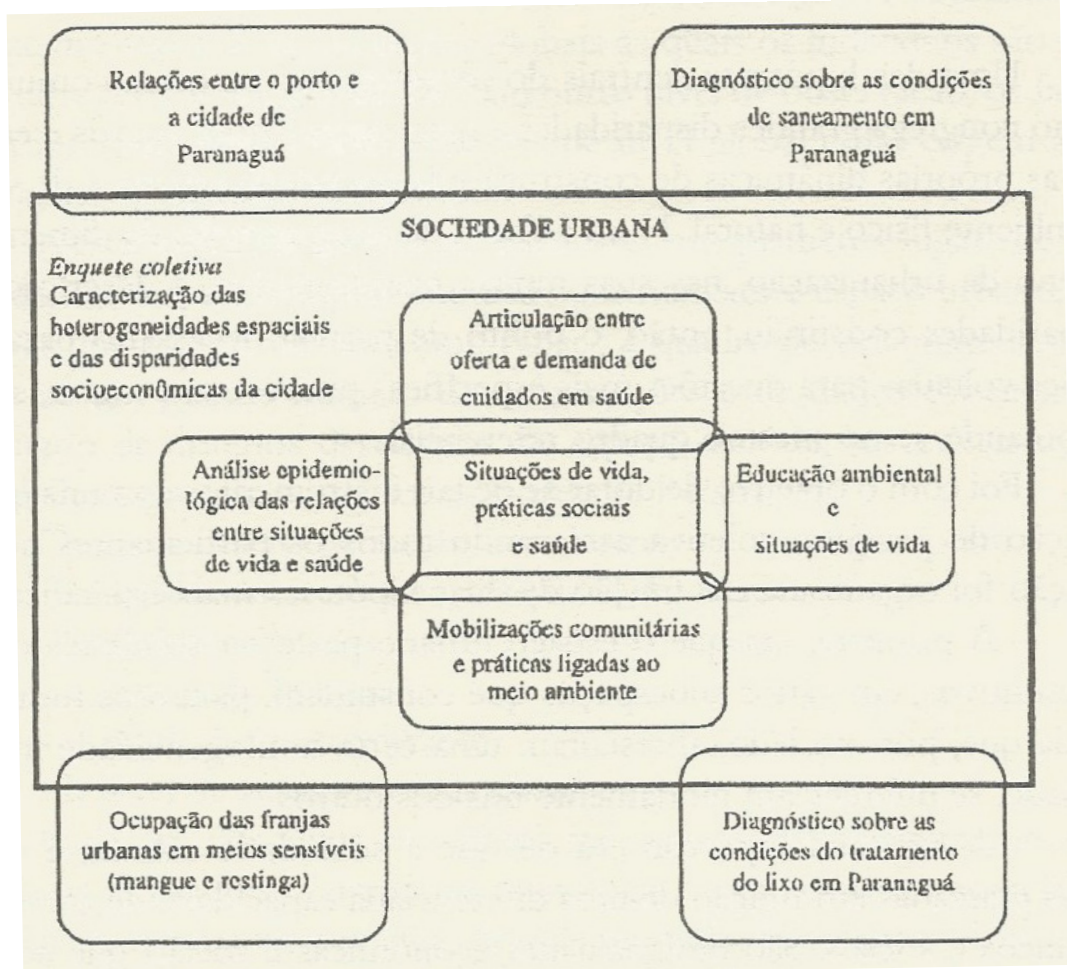

FIGURA 2 - Articulação dos projetos de pesquisa em Paranaguá. 
uma boa interpenetração das teses e a centralidade de algumas questões de forma transversal às pesquisas individuais. Alguns alunos não conseguiram aceitar a ideia de integrarem sua própria pesquisa dentro de um projeto intelectual coletivo. Isso remete a um dos grandes limitantes do enfoque interdisciplinar. Tal como a experiência já confirmou em vários outros casos ${ }^{1}$, ele só funciona quando cada um dos participantes tem o desejo pessoal de participar numa aventura comum. $\mathrm{O}$ Doutorado não escapa à regra das forças centrífugas e das reafirmações de identidade que proporciona o recorte disciplinar (cf. Introdução). No entanto, a maioria dos membros da equipe conseguiu conciliar sua atuação científica individual com a manutenção de relações fortes dentro do grupo. Isto, em particular, fez-se no contexto de operações de pesquisa coletivas e de oficinas de pesquisa periódicas que foram iniciadas após a escolha definitiva de Paranaguá como local de estudo e a elaboração do quadro de problemática comum.

\section{A fase de construção de instrumentos de trabalho comuns}

Uma das hipóteses centrais do programa de pesquisa comum era que o meio urbano congrega grandes disparidades e heterogeneidades sociais e espaciais, que expressam as próprias dinâmicas de construção da sociedade urbana e de suas relações com seu ambiente físico e natural. Num esforço de compreensão da dimensão humana do fenômeno de urbanização, nas suas muitas manifestações, a descrição e a análise destas disparidades constituiu, então, o ponto de partida necessário para que outras investigações voltadas para questões mais específicas pudessem, a seguir, serem desenvolvidas, apoiando-se no mesmo quadro referencial.

Foi com o objetivo de dotar-se de tais instrumentos comuns que se lançou uma operação de pesquisa coletiva associando todos os participantes no programa. Esta operação foi organizada em função de duas hipóteses mais específicas:

- A primeira, era que o espaço urbano pode ser subdividido, a partir de critérios descritivos, em vários subespaços que constituem, para seus moradores, quadros de vida que, por um lado, apresentam uma certa homogeneidade interna e que, por outro lado, se diferenciam nitidamente uns dos outros.

- A segunda hipótese era de que a sociedade urbana é dividida por disparidades marcadas em função de uma diferenciada capacidade de acesso aos recursos econômicos e sociais. São desigualdades econômicas e sociais que se manifestam desta forma e que podem ser observadas e analisadas a partir de critérios descritivos e modos de investigação adequados.

Os dois ângulos de análise conduziram então a elaborar distintos instrumentos de apreensão das heterogeneidades e disparidades urbanas: um zoneamento espacial da cidade e uma estratificação socioeconômica de seus habitantes. Eles poderiam ser cruzados entre si, levantando-se assim a questão da convergência ou da divergência que se encontra entre as imagens que evidenciam dessas heterogeneidades e disparidades. Ou seja: até qual ponto, e de qual forma, a diversidade dos quadros de vida que oferece o espaço urbano reflete as desigualdades

\footnotetext{
1 Vários seminários e colóquios têm discutido os alcances e a validade dos projetos interdisciplinares e têm apontado esta dificuldade.Pode-se citar os exemplos do Workshop Ciências Sociais, Ciências Naturais, Meio Ambiente e Desenvolvimento: as pesquisas interdisciplinares na América e na França, promovido pela UNICAMP, UFPR, EMBRAPA e Revista NSS (Campinas, 1996) e o seminário L'évaluation scientifique: objets complexes et approches interdisciplinaires dans le domaine de l'environnement - acteurs, structures, enjeux et questionnements, promovido pela Revue NSS (Paris, Journées, 1998).
} 
socioeconômicas que dividem a sociedade urbana? $\mathrm{Ou}$, ainda, qual é a ligação entre o fato de pertencer a um dado estrato socioeconômico e o de morar numa certa parte da cidade?

É claro que existem bairros pobres e ricos em Paranaguá, como em qualquer outra cidade brasileira. Mas, a realidade pode ser muito mais complexa do que a redescoberta desta evidência. É a variabilidade em relação à tendência geral que pode ser reveladora de dinâmicas, de estratégias coletivas ou individuais. Ela, entre outros indicadores, pode oferecer uma porta de entrada para analisar a tensão entre contexto global e jogo dos atores sociais, que constitui o cerne do conceito de situação de vida.

Além disso, o objetivo da elaboração desses dois instrumentos era fornecer, a cada pesquisador do grupo, um mesmo referencial de descrição das heterogeneidades urbanas, viabilizando-se assim as aproximações e cruzamentos entre achados oriundos de campos disciplinares diferentes.

\section{O zoneamento da cidade de Paranaguá}

Para descrever uma cidade como Paranaguá e para analisar os processos que contribuem para sua evolução espacial, social e econômica, prioridades foram fixadas em função das necessidades desta fase da pesquisa. Nesse aspecto a cartografia foi, sem dúvida, o instrumento mais adaptado, pois permitia caracterizar subespaços urbanos ou zonas, no interior dos quais convergem características próximas. Proceder a um zoneamento não implicava pensar, em nenhum momento, que comportamentos individuais e coletivos seriam idênticos no interior de cada subespaço delimitado. Significava simplesmente mostrar que as condições globais às quais os indivíduos são submetidos apresentam uma certa homogeneidade. Em outro nível de observação, os fatores locais podem vir a interferir nesses determinantes de nível global e dar origem a diferenças entre as situações observadas em campo.

Nesta etapa da pesquisa, tratou-se, em primeiro lugar, de analisar as heterogeneidades e rupturas de continuidade que marcam o espaço urbano, valendo -se de indicadores que o caracterizam como espaço e quadro de vida materiais. Para ordenar a coleta de um grande número de informações e de dados, foi selecionado um número limitado de critérios descritivos do espaço de vida, suscetíveis de indicar as heterogeneidades espaciais existentes na cidade de Paranaguá.

Os eixos de diversificação inicialmente selecionados foram:

- a história do crescimento espacial da cidade;

- as funções urbanas e a oferta de serviços;

- a densidade humana;

- o nível socioeconômico;

- o nível de acesso ao saneamento.

Cada um dos eixos escolhidos foi expresso de maneira concreta através de um ou vários indicadores empíricos: cronologia do crescimento espacial da cidade, número médio de habitantes por área, tipo de moradia, valor imobiliário, consumo de energia elétrica, ligações clandestinas de água e instalações sanitárias inadequadas. A coleta das informações relativas a esses indicadores baseou-se em fontes secundárias, estudos básicos realizados na cidade de Paranaguá, em 1995, pela equipe de doutorandos da UFPR e também observações de campo realizadas em janeiro e fevereiro de 1996. As técnicas de análise do espaço urbano concentraram-se, sobretudo, na utilização da cartografia informatizada (Cabral 1500), interpretação de fotografias aéreas, levantamentos de campo, análises estatísticas de bases de dados disponíveis (Censo Demográfico 1991 do IBGE, relatório cadastral 1996, da CAGEPAR, consumo de energia elétrica de abril 95 a março 96, da COPEL). 
Cada um desses indicadores deu origem a um mapa temático. Numa segunda etapa, os mapas foram sobrepostos conforme a árvore de cruzamento na Figura 3, que expressa a hierarquia das diferentes variáveis levadas em consideração para descrever umas das muitas heterogeneidades do espaço urbano.

Para chegar a um zoneamento que fosse uma síntese das variações particulares de cada um dos critérios, foi necessário introduzir uma ordem na combinação destes muitos recortes espaciais. Por isso, utilizou-se um indicador que se poderia chamar de "fio condutor", pois ele se reflete praticamente em cada um dos mapas temáticos: trata-se da cronologia do crescimento espacial da cidade e das áreas sucessivas de extensão do perímetro urbano que ela determinou. Em várias ocasiões, pôde-se identificar a história mesma da cidade e de seu desenvolvimento no espaço através das diferenças encontradas pelos critérios que descrevem a realidade da cidade de hoje: funções urbanas, densidade humana, tipo de moradia, etc.

O resultado ao qual se chegou, através da elaboração deste instrumento, foi a divisão da cidade de Paranaguá em três zonas principais (recorte principalmente baseado na história) e oito subzonas, que introduzem nuances ligadas à variação observada nos outros eixos de diferenciação apresentados acima. A este recorte da própria aglomeração urbana acrescentou-se uma quarta zona (subdividida também em duas subzonas), cuja identificação foi feita a partir de um critério espacial específico: tratase da Ilha de Valadares, separada do continente por um braço do rio Itiberê, que hoje pertence à cidade, mas que teve uma história diferente e que apresenta características físicas e socioculturais bem particulares.

Após ter sido verificado e finalizado, utilizando-se variáveis externas, isto é, variáveis que não foram utilizadas na elaboração do zoneamento inicial

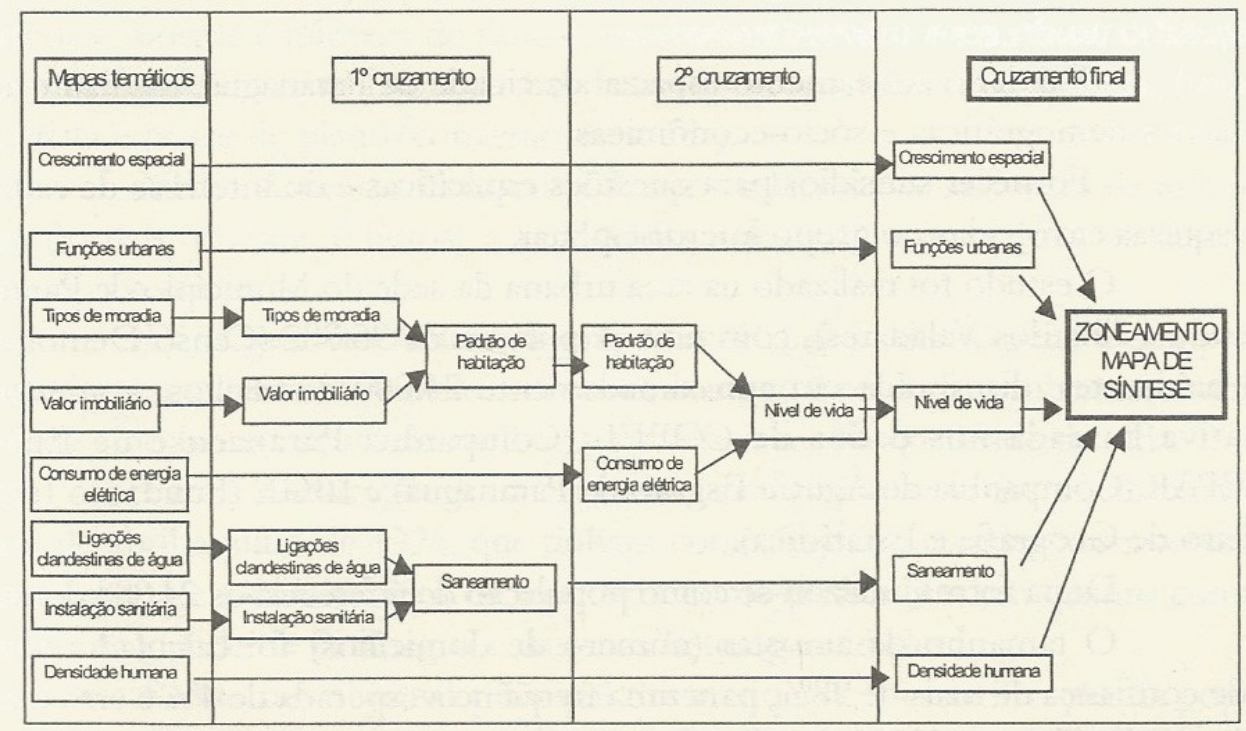

FIGURA 3 -Árvore de cruzamento de mapas temáticos. 
e que foram levantadas numa enquete domiciliar, realizada na sequência do trabalho coletivo (cf. no próximo item), agruparam-se algumas subzonas por estas não apresentarem diferenças significativas. $\mathrm{O}$ resultado final deste zoneamento acabou por fixar em cinco as grandes zonas de Paranaguá (Figura 4) e constituiu a base de descrição das heterogeneidades espaciais da cidade, instrumento comum a todos os pesquisadores da equipe.

\section{A enquete domiciliar e a estratificação social}

A segunda operação comum aos diferentes doutorandos foi a realização de uma enquete domiciliar, através de um modelo de estudo seccional ou transversal (survey), em que a unidade básica do estudo foi o domicílio e que teve três objetivos distintos:

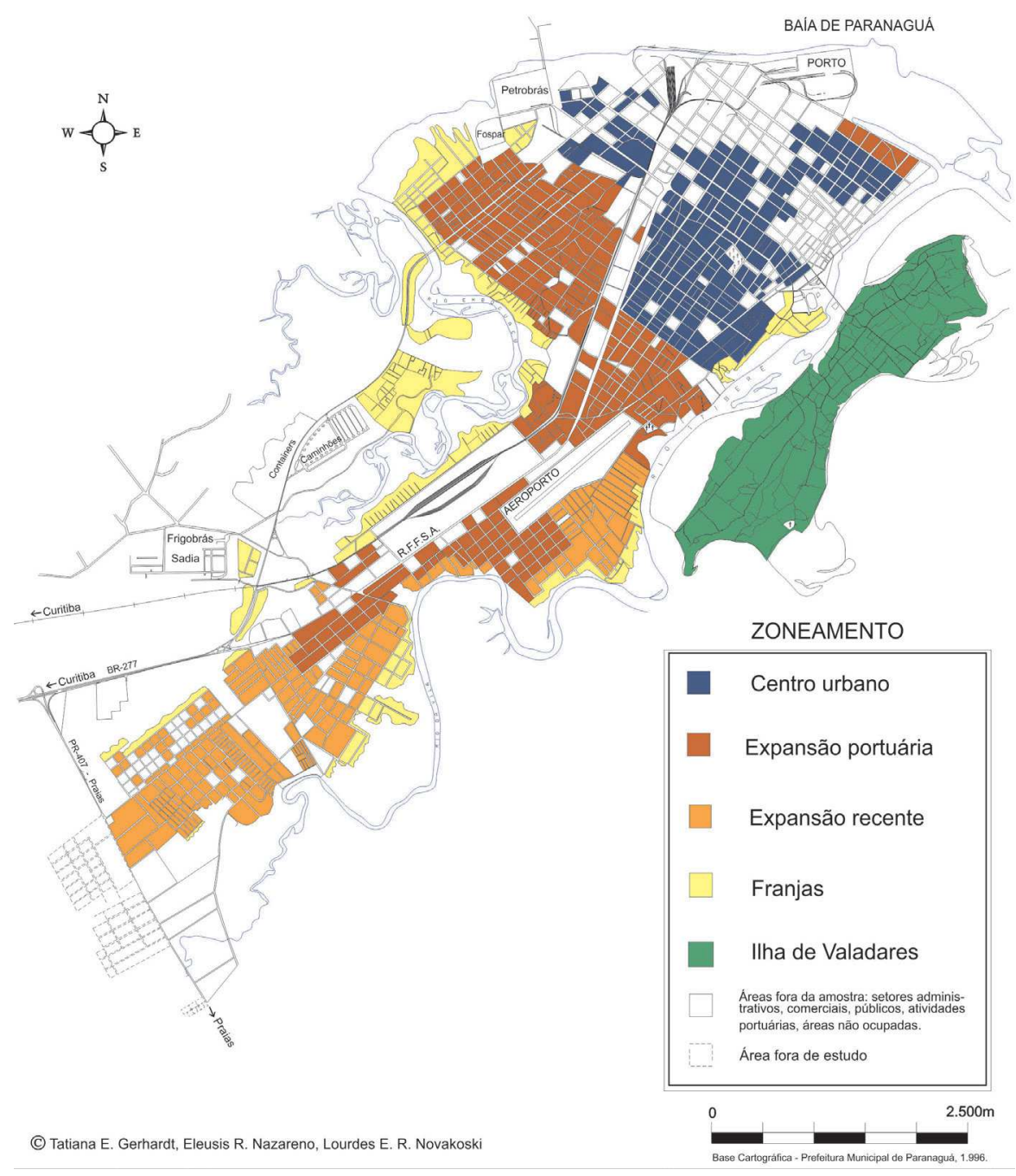

Figura 4 - Zoneamento da cidade de Paranaguá. 
- representar as disparidades da sociedade parnanguara, através da elaboração de um modelo de estratificação socioeconômica que pudesse ser utilizado por si mesmo ou cruzado com o zoneamento;

- validar o zoneamento espacial da cidade de Paranaguá, mediante o uso de variáveis demográficas e socioeconômicas;

- fornecer subsídios para questões específicas e do interesse de cada uma das pesquisas envolvidas no grupo interdisciplinar.

O estudo foi realizado na área urbana da sede do Município de Paranaguá (incluindo a Ilha dos Valadares), com uma população de 95.782 (Censo Demográfico, 1991) habitantes, distribuída em aproximadamente 24.000 domicílios, segundo uma estimativa baseada nos dados da COPEL (Companhia Paranaense de Energia), CAGEPAR (Companhia de Água e Esgoto de Paranaguá) e IBGE (Fundação Instituto Brasileiro de Geografia e Estatística).

Desta forma, utilizou-se como população de referência os 24.000 domicílios.

O tamanho da amostra (número de domicílios) foi calculado com um nível de confiança de mais de $98 \%$, para uma frequência esperada de $4 \%$ e erro máximo de $2 \%$, resultando em 600 domicílios a serem entrevistados. A seguir, a amostra foi estratificada nas zonas e subzonas obtidas anteriormente com partilha proporcional ao tamanho das mesmas em número de domicílios. Efetuou-se uma correção para até 20 domicílios nas subzonas com números inferiores a este e foram acrescentados alguns domicílios na amostra para compensar áreas novas de crescimento da cidade que não haviam sido contempladas no universo inicial, resultando num total de 639 como amostra real.

Para o sorteio dos domicílios, utilizou-se o banco de dados da CAGEPAR, que dividia e numerava a cidade em setores, quadras e lotes (domicílios), realizando-se uma equivalência com o zoneamento efetuado e, em seguida, a partir do número de domicílios definido para a amostra de cada zona e subzona, efetuou-se o sorteio das quadras, seguido do sorteio do lote em cada quadra, ambos por meio da geração de números aleatórios.

O levantamento dos dados foi realizado por meio de um questionário, constituído de dez partes, correspondendo às necessidades e interesses comuns ao grupo. A primeira página contém informações e dados sobre a localização espacial do domicilio (zona, subzona, setor, quadra, lote, bloco, unidade e endereço do domicílio) e dados de identificação do instrumento, do entrevistador e do supervisor. Na sequência, foram levantados dados relativos a cada domicílio:

I - Identificação - contempla dados sobre a composição da estrutura familiar (nome, chefe, informante, posição na estrutura familiar, idade, sexo, estado civil), local de nascimento e tempo de moradia no atual domicilio.

II - Migração e Mobilidade Residencial - refere-se à origem do chefe de família, migrações intermediárias e migração para Paranaguá, no caso de não ter nascido nessa cidade, assim como a mobilidade residencial no interior da cidade e motivos que levaram a escolher a residência atual.

III - Características do Domicílio - contém informações sobre habitação (tipo de moradia, condições de habitação, posse de bens de consumo duráveis), ambiente peridomiciliar (características do terreno) e saneamento (água, esgoto e lixo).

IV - Escolaridade - refere-se a dados de escolaridade (grau de ensino, tipo de escola frequentada, motivo pelo qual não frequenta ou não frequentou a escola).

V - Ocupação/Trabalho - em relação ao chefe de família foram levantados dados sobre sua situação ocupacional (se está trabalhando, como e onde trabalha e profissão) e situação ocupacional de outros membros da família. 
VI - Vida e Participação Social - neste item são levantados aspectos relativos a laços familiares, relações comunitárias, participação em organizações da sociedade civil e religião.

VII - Saúde - contempla dados relativos à fecundidade (número de nascidos vivos e mortos e número de filhos), morbidade recente e existente, utilização dos serviços de saúde em ambulatórios e hospitais (tipos, itinerários terapêuticos, frequência ao dentista e posse de plano/convênio de saúde).

VIII - Aspectos Culturais e Lazer - relaciona-se às fontes de informação escrita (jornais, revistas e livros) e oral (rádio, televisão) e às opções de lazer como passatempo e em férias.

IX - Questões Ambientais do Meio Urbano diz respeito à compreensão que o informante tem sobre meio ambiente, mangue e restinga, problemas ambientais da cidade e do bairro, ações de melhoria e referenciais de qualidade de vida.

Para a elaboração do questionário, realizaram-se várias oficinas do grupo urbano de abril a julho de 1996, que tinham como objetivo atender aos interesses comuns ao grupo e a cada projeto de tese, bem como possibilitar um quadro comum de descrição da cidade de Paranaguá e das suas heterogeneidades.

Sendo um objetivo principal desta enquete, a estratificação da população urbana em relação às disparidades socioeconômicas, foi feito um trabalho de reflexão comum em relação à definição dos critérios concretos a serem utilizados para caracterizar o nível de renda das famílias. Ao final, escolheram-se os seguintes critérios ${ }^{2}$ :

- tipo de moradia (material de construção e material de cobertura);

- densidade habitacional (número de morado$\mathrm{res} / \mathrm{m}^{2}$ do domicílio);
- escolaridade do chefe da família (nível de escolaridade em anos de estudo);

- número de banheiros (número de banheiros existentes no domicílio);

- bens de consumo e serviços (tipo de bens de consumo existentes no domicílio, como: máquina de lavar roupa, videocassete, freezer, e a existência e o número de bens como carro, telefone, televisão em cores, rádio, e a existência de serviço de empregada doméstica mensalista).

O questionário foi submetido a um teste aplicado pelos próprios membros do grupo de pesquisa do meio urbano. Para tanto, cada doutorando aplicou três questionários nas diferentes zonas e subzonas para verificar a consistência, o entendimento e a clareza das questões. Após a aplicação, foram feitos os ajustes necessários na sua forma definitiva e realizou-se a coleta dos dados (entre agosto e dezembro de 1996).

Antes da ida a campo, seguiu-se uma fase de treinamento de 10 entrevistadores para a aplicação do questionário propriamente dito. Estes tinham formação mínima de segundo grau, experiência em levantamento de dados de campo e conhecimento da cidade. Essa fase de treinamento envolveu o conhecimento do questionário, englobando os objetivos de cada pergunta, as maneiras de abordagem/ encaminhamento das questões junto ao entrevistado e a organização da distribuição do questionário. É importante salientar que, antes do início da coleta de dados pelos entrevistadores, os mesmos o testaram entre si para sanar as possíveis dúvidas existentes. Para sistematizar o trabalho e haver um elo de ligação entre entrevistadores e doutorandos, foi constituída uma coordenação local que organizava a distribuição e o recebimento dos questionários. Por

\footnotetext{
2 Mais detalhes sobre a metodologia de elaboração deste indicador são apresentados em Gerhardt, T. E.; Nazareno, E. R.; Novakoski, L. E. R. dezembro 1997.
} 
sua vez, os doutorandos controlavam os recursos, a distribuição dos questionários, a checagem dos dados coletados e as dificuldades que surgiam, entre as quais a inconsistência dos dados coletados e o treinamento de novos entrevistadores. Os questionários preenchidos passavam pela supervisão tanto da coordenação local quanto da dos doutorandos. Em caso de problema, o questionário voltava às mãos do entrevistador que o tinha aplicado, para ser corrigido junto ao mesmo entrevistado.

Após a digitação e organização de um banco de dados, utilizando-se o programa EPI-INFO versão 6.04, fez-se a sua distribuição entre os doutorandos da pesquisa do meio urbano. Após várias reuniões, sob orientação de três professores do curso, foi discutida a metodologia de análise dos dados.

Para a análise dos itens I ao VII, foi feita a distribuição de partes dos dados a cada doutorando, ficando cada qual responsável pelas sistematizações e categorizações pertinentes à sua área de pesquisa e/ou de interesse.

Para a análise dos itens VIII e IX, cujas respostas foram dadas de forma aberta, criou-se uma subequipe composta de cinco doutorandos que ficaram responsáveis pelas questões relativas a determinadas zonas e/ou subzonas.

Ao longo do processo, foram realizados, com participação de alunos e professores, vários seminários, durante os quais expuseram-se os resultados parciais para troca de informações e contribuições coletivas. Concomitantemente, ocorreram articulações eventuais de alguns doutorandos entre si, em função das competências de cada disciplina. A enquete domiciliar permitiu, assim, a produção de análises temáticas que deram origem a vários relatórios e subsídios aos trabalhos de tese de cada doutorando.

Utilizando-se os critérios de avaliação do nível de vida apresentados anteriormente, foi elaborada uma estratificação socioeconômica, através da aplicação do método estatístico multivariado de análise fatorial de correspondências múltiplas, com o programa SPAD.N integrado versão 2.5 , chegando-se a quatro estratos básicos: A (21 famílias), B (201 famílias), C (240 famílias) e D (177 famílias). Esse método foi escolhido pelo interesse em realizar análises simultâneas das relações entre os diversos critérios definidos para caracterizar o nível de vida. Após a análise do comportamento praticamente semelhante dos estratos A e B com relação a uma série de outras características obtidas na enquete, fez-se um agrupamento dessas duas classes e o modelo final compreendeu três estratos: superior (222 famílias), médio (240 famílias), inferior (177 famílias).

A validação do zoneamento espacial - segundo objetivo da enquete - foi finalizada através da análise estatística comparativa entre subzonas de algumas variáveis ligadas a indicadores sociais e demográficos já utilizados no próprio processo de zoneamento: densidade demográfica, padrão habitacional, saneamento, etc. O resultado foi o agrupamento de várias subzonas que, correlacionadas com estas variáveis, não evidenciavam diferenças significativas. Isso resultou em um zoneamento final reduzido a cinco zonas, como já se disse no item anterior.

O cruzamento da estratificação socioeconômica e do zoneamento espacial permitiu confirmar a hipótese metodológica inicial: a de diferenças na repartição dos estratos, segundo os espaços da cidade, diferenciando-se claramente as zonas em função do nível de vida médio da sua população residente. Mas, ele evidenciou também a presença de todos os estratos em todas as zonas, embora em proporções diferentes. Encontram-se então famílias bem abastadas em áreas cujas características ambientais globais são péssimas, bem como famílias miseráveis em bairros que apresentam um quadro de vida de alto padrão. Isso remete claramente a nuanças, trajetórias, estratégias que somente podem ser analisadas levando em 
conta a atuação dos atores sociais e sua capacidade de participar da construção de sua situação de vida. A Figura 5 ilustra o resultado desse cruzamento.

Esses dois instrumentos de descrição de uma realidade urbana diversificada foram disponibilizados para todos os pesquisadores do grupo a fim de que utilizassem em seu próprio trabalho de tese. Uma última oficina foi realizada para sistematizar os dados trabalhados e analisados pelos doutorandos, de forma a constituir uma base de dados única e comum a todos. Nesse processo de sistematização e análise dos dados, cada doutorando trouxe sua colaboração de acordo com seus interesses e necessidades.

\section{Das operações coletivas de pesquisa para as teses individuais}

O quadro comum de descrição das heterogeneidades e disparidades da sociedade urbana e do espaço da cidade apresentado acima, além de cons- tituir a base do diálogo interdisciplinar entre todos os membros da equipe, proporcionou o levantamento de questões para o aprofundamento nas teses individuais e também o redirecionamento de algumas delas. Um grande aporte propiciado por essas etapas iniciais do trabalho interdisciplinar foi a possibilidade de uma abordagem global da realidade estudada. Isso permitiu terem as teses a mesma referência inicial para descrever a cidade e seus habitantes e serem as investigações específicas relacionadas a um contexto mais amplo em parte já conhecido.

Um ponto a ser destacado em todo o processo vivenciado pelos alunos foi o de como enfrentar as necessidades do desenvolvimento de operações coletivas de pesquisa e articulá-las aos seus trabalhos específicos de tese. Num primeiro momento, quando se partiu para a pesquisa de campo, havia uma grande preocupação, de natureza individual, em coletar os dados que cada um dos trabalhos exigia de acordo com as hipóteses individuais. Isto provocou tensões sobre o nível de aprofundamento de cada etapa da

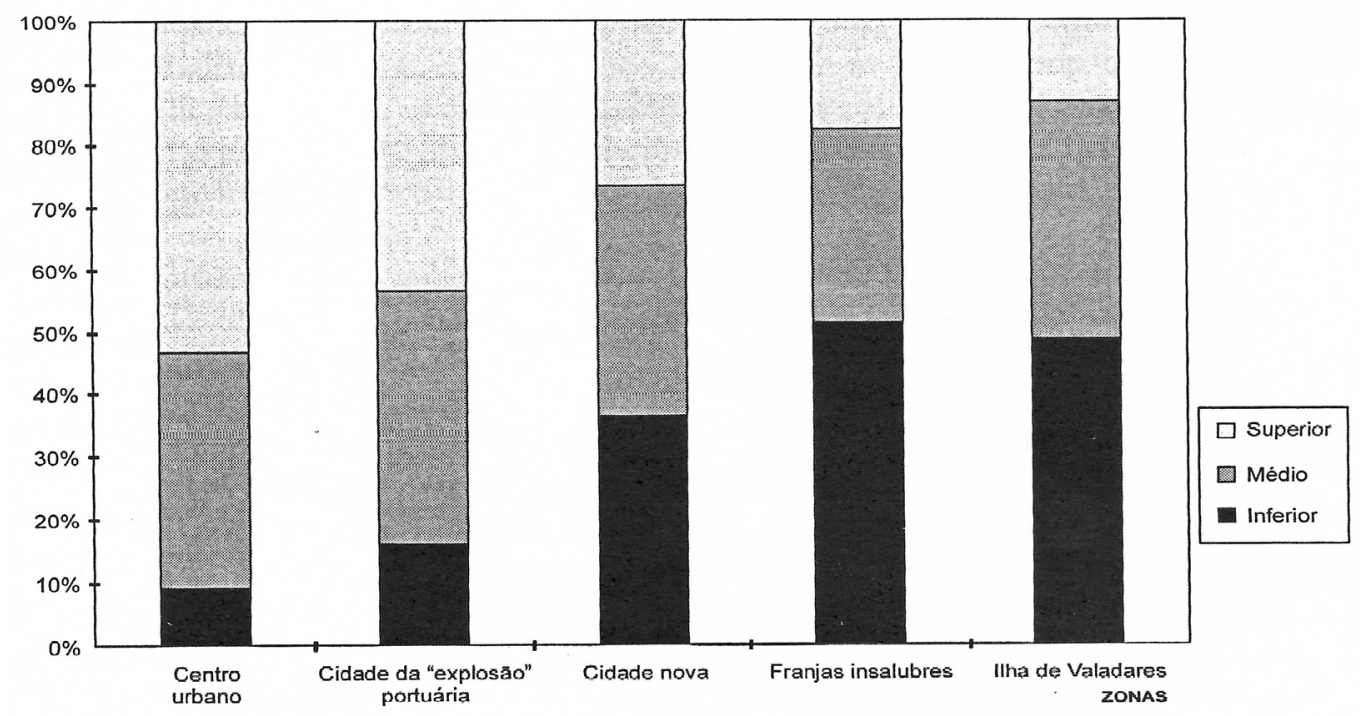

FIGURA 5 - Distribuição dos estratos sociais nas diferentes zonas da cidade de Paranaguá. 
pesquisa coletiva: houve uma grande dificuldade em se compreender a necessidade de operações comuns, que pudessem gerar instrumentos comuns de análise e a produção de informações de nível mais geral, que alimentariam as pesquisas individuais, mas não supririam todas as suas necessidades. Não se tratava de um trabalho de equipe com divisão de tarefas e superposição dos trabalhos individuais, mas de um trabalho de equipe com distribuição de tarefas em função de objetivos e uma metodologia comum. Por outro lado, houve interpretações no sentido de que esse trabalho em equipe devesse gerar um texto único, escrito por várias pessoas, a ser utilizado em todas as teses da mesma forma, o que não estava de acordo com a concepção da interdisciplinaridade que inspirou a criação do doutorado. Na verdade, tratava-se de elaborar instrumentos de análise comuns da mesma realidade e resultados gerais de pesquisa a serem utilizados por cada um, de forma diferenciada, de acordo com os objetivos e enfoques de seus trabalhos específicos.

Esse processo de construção gradativa do programa de pesquisa, desde o diagnóstico inicial da região de estudo, que resultou na escolha da cidade de Paranaguá, aos estudos do espaço urbano, validados pela enquete domiciliar e, por fim, a diferenciação da população, segundo os estratos, desenvolveu-se por reflexões coletivas e aproximações sucessivas da realidade a ser estudada, enriquecendo substancialmente os trabalhos de tese individuais desenvolvidos posteriormente. Isto não seria possível através de um processo de escolha pura e simples de temas individuais de pesquisa, mesmo que num mesmo espaço, nem pelo desenvolvimento de um programa de pesquisa com repartições de áreas estanques de investigação, sem um quadro conceitual comum previamente definido.
Entretanto, deve-se ressaltar que, dentro das exigências deste tipo de trabalho, são privilegiadas, necessariamente, as discussões em grupo, a organização de trabalhos em equipes, as operações coletivas, tanto de construção de instrumentos como de coleta de dados, a troca de informações permanente e a análise conjunta de dados para obtenção das conclusões. Tais processos já não são isentos de tensões e conflitos em trabalhos meramente disciplinares. Tratando-se de um trabalho interdisciplinar, é necessário um esforço adicional de superação das barreiras disciplinares e a disposição a transpor fronteiras para o intercâmbio produtivo de ideias, contribuindo com a sua competência específica para o trabalho coletivo, sem ceder à tentação de abandonar seu campo disciplinar para abraçar outros domínios que não são seus. Os conflitos intelectuais, por sua vez, fazem parte do próprio processo interdisciplinar e são importantes para clarear as posições, as ideias e os papéis de cada um, e também para contribuir na evolução das reflexões que levem a intercâmbios úteis para a resolução dos problemas enfrentados no trabalho de equipe.

Os capítulos a seguir resgatam alguns dos resultados dos trabalhos individuais que foram conduzidos no âmbito do programa de pesquisa "Espaço Urbano, Situações de Vida e Saúde: o caso de Paranaguá", através do processo interdisciplinar cujas grandes linhas acabamos de descrever. Os três primeiros textos trazem elementos que ajudam a entender o contexto econômico, social e ambiental da cidade. Os dois outros são mais diretamente voltados para questões de saúde, sendo que o último deles é fruto de um trabalho coletivo, síntese dos resultados de duas teses, realizadas de maneira estreitamente articulada por uma epidemiologista e por uma antropóloga. 